\title{
Las formaciones léxicas en -ivo en la traducción castellana del libro De las Propiedades de las Cosas de Bartolomé Ánglico: ¿latinismos, neolatinismos o neologismos?
}

\author{
ENRIQUE JIMÉNEZ RÍOS \\ Universidad de Salamanca
}

\begin{abstract}
Resumen
El artículo estudia las formaciones léxicas en -ivo de la traducción castellana que fray Vicente de Burgos hizo en el siglo XV del libro De las Propiedades de las Cosas de Bartolomé Ánglico, importante enciclopedia medieval. Se analiza la presencia y frecuencia de uso de formas como 'agregativo' u 'odorativo', al lado de 'creativo' o 'nutritivo', a través de la consulta de otros textos y diccionarios (corpus ADMYTE y CORDE) y de la versión latina del texto, donde se registran ya dichas formaciones. Se revisan los conceptos de 'latinismo' y 'neolatinismo' aplicados a ese tipo de voces y se plantea, con el apoyo en el texto base de la traducción, que el mantenimiento obedece a la actitud latinizante del autor, que latiniza a través del léxico, de la sintaxis y de la construcción textual.
\end{abstract}

\begin{abstract}
The article studies the lexical formations in - ivo found in the 15th-century Castilian version of Bartholomaeus Anglicus' De proprietatibus rerum, translated by Vicente de Burgos. The article includes a side-by-side analysis of the occurrence and frequency of forms such as 'agregativo' or 'odorativo' and 'creativo' or 'nutritivo' in other texts and dictionaries (ADMYTE and CORDE corpora) and in the Latin version of the text that already register this lexical formations. The articles re-examines the concept of 'Latinism' and 'Neolatinism' applied to these forms, and, based on the translation, posits that they are preserved due to the Latinizing attitude of the author, seen in the lexicon, syntax, and textual construction.
\end{abstract}




\section{Introducción}

El uso de 'neolatinismo' en el título de este artículo obliga a que las primeras palabras estén dirigidas a su explicación: 'neolatinismo' es la denominación utilizada por Pharies (2002: 371) para referirse a creaciones léxicas que imitan formas latinas o se crean según el modelo latino; señala que en el siglo XV 'al mismo tiempo que aparecen los primeros latinismos, se comienzan a construir neolatinismos'. Y cita, con sufijo -ivo (lat. -Ivus), de aparición tardía en español, voces como nauseativo (1495), nutritivo (1440) o pensativo (1438), documentadas en textos médicos de esa centuria, recogidos en ADMYTE.

La lectura del libro De las Propiedades de las Cosas (PDC), de Bartolomé Ánglico (o Glanville), ${ }^{1}$ importante enciclopedia medieval - a la luz de las traducciones efectuadas sobre el original latino al castellano y otras lenguas románicas ${ }^{2}-$ revela la presencia de distintas formas con sufijo -ivo, susceptibles de recibir distintas interpretaciones, pues, aunque muchas sean corrientes en ese momento, la suerte en la historia del léxico español es distinta: no es lo mismo encontrar virtud generativa o virtud motiva, que virtud ampleativa ${ }^{3}$ o virtud odorativa; tampoco, como adjetivos aislados, creativo o provocativo que agregativo o manifestativo. Precisamente para poder explicar la naturaleza de estos adjetivos en el texto, me fijo, por un lado, en otros textos literarios y no literarios fechados en el mismo siglo; y, por otro, en la situación que presenta la fuente latina de la enciclopedia a través de uno de sus testimonios conservados. ${ }^{4}$ Con ello pretendo, además, hacer una contribución a la morfología derivativa del español, desde una perspectiva histórica, a través de un sufijo, -ivo, que no ha recibido mucha atención por parte de los investigadores (Fernández Ramírez 1975: 323), quizá porque el análisis se ha limitado a la sincronía, ${ }^{5}$ dejándose así de lado el desarrollo histórico (Pascual 1996: 40-41; Pharies 2002).

\section{Formaciones léxicas en -ivo: presencia y representatividad en otros textos}

De las formas con -ivo existentes en el PDC (véase apéndice) la mayoría está documentada en el DECH; a pesar de ello, las no documentadas son también abundantes: aleviativo (aliviativo), ampleativa (ampliativa), combustiva, concretivos, consumativas, consumitivos, corruptivas, descolorativo, desecativas, disolutivo, endurativa, enflamativas (inflamativos), engendrativo, exemplificativo (ejemplificativo), extenuativo,

1 Enmarcada en un proyecto de investigación de carácter lexicográfico titulado "Diccionario español de textos misceláneos antiguos" financiado por la Dirección General de Investigación del Ministerio de Educación y Ciencia de España (HUM2004-00748).

2 El texto castellano es el siguiente: Bartholomaeus Glanville, Propiedades de las Cosas. De Proprietatibus Rerum. Bartolomé Ánglico; Translated by Fray Vicente de Burgos. Tolosa, 1494-9-18. Enrique Mayer. BNM Cat 266 (I 1884).

3 Aunque ampliativa está en el DRAE (22 ed.).

4 Se trata del texto conservado en la Biblioteca Nacional con la signatura BNM inc. 2456, Proprietates rerum domini bartholomei anglici.

5 Las gramáticas, diccionarios y morfologías del español se limitan a explicar el tipo de base a la que se añade -ivo y el valor que aporta. 
generativo, infectivos, judicativa, mortificativa, mutativo, odorativa, pacitiva, percusivas, pulsiva, pungitivo, redutivo, -a (reductivo, -a), remolitivas, reparativo, resolutivos, tardivo, transumptivos y vaporativo. Con las que se documentan es posible establecer dos grupos: uno, en el que las voces no tienen información bibliográfica; sólo tienen el testimonio de su documentación (son casi la mitad y aparecen en el apartado de derivados, cultismos o compuestos y no tienen información etimológica o histórica); otro, en el que sí se da esa información (la fuente casi siempre es Smith 1959). ${ }^{6}$ A este grupo pertenecen las catalogadas como latinismos cultos, utilizadas por autores como Alfonso de la Torre, Mena, Villena o Fernández de Villegas, obras como El Corbacho o repertorios léxicos como el de Palencia o la traducción del Discórides que hizo Laguna, aunque la documentación sobresaliente es Alfonso de la Torre, de 1440. El DECH confirma, entonces, la aparición de estas voces en la lengua: en obras latinizantes del siglo XV o a través de glosarios y vocabularios; y para las no documentadas su falta orienta acerca del carácter novedoso o 'neolatino'?

Otro apoyo documental lo ofrece el CORDE. Destacan las formas aleviativo (aliviativo), apurativo, colorativos, concretivos, consumptivo, conversivo, descolorativo, exemplificativo (ejemplificativo), engendrativo, extenuativo, inmutativa, ordenativos, redutivo (reductivo), remolitivas, reparativo, sotiliativa, suçeptiva, tardivo, transumtivos y vaporativo, documentadas en el corpus sólo con el testimonio del $P D C,{ }^{8}$ coincidiendo con muchas de las que no están en el $\mathrm{DECH}$. Las que están en el corpus lo hacen preferentemente en textos científico-técnicos. ${ }^{9}$

Otros textos de distinta naturaleza no recogen estas formaciones en -ivo: si se toman, por ejemplo, las voces en -ivo estudiadas aquí, no documentadas en el $D E C H$, se comprueba, al consultar los índices léxicos de ADMYTE, que tampoco están en los textos de ese corpus. En cambio, el corpus de textos médicos del DETEMA, también del siglo XV, presenta diferencias y semejanzas con el PDC, ya que unas formas están y otras no. ${ }^{10}$

Esta situación de ausencia generalizada de estas voces en textos de distinta naturaleza, preferentemente literarios, a pesar de la sola documentación en el

6 Es frecuente también ver en el $D E C H$ la voz derivada sin información bibliográfica (por ejemplo, inflamativa) y la base de derivación (inflamar) como voz tomada de Smith (1959).

7 Las cifras son reveladoras del tipo de voces de que se trata: de 166 formas, 32 no se recogen, 75 sólo tienen el testimonio de su documentación y en las 60 restantes con información bibliográfica, 28 pertenecen a la recopilación de Smith. Si las voces que no se recogen y las que sólo tienen el testimonio de su documentación son la mayoría, eso indica su peculiaridad: no son propias de la lengua literaria, ni de las grandes obras de la literatura.

8 La no documentación en el CORDE puede estar motivada por la falta de textos en ese corpus: es posible que en otros textos sí aparezcan. Claro que, teniendo en cuenta que en el CORDE hay textos científicos y técnicos, coetáneos del PDC y de fechas posteriores, y que el PDC es una enciclopedia cuyo léxico es pretendidamente general, la sola documentación en este texto de algunas de las palabras ha de explicarse más por la peculiaridad del texto que por el conjunto de textos (o por la falta de textos) que conforman el CORDE.

9 La frecuencia de aparición es mayor en textos científico-técnicos (cuando no aparecen sólo en este tipo de textos). Vid. www.rae.es/corde.

10 No está aleviativo, descolorativo o extenuativo; en cambio, otras como espesativo, jocundativo, potativo o succitivo, están en el DETEMA y no en el PDC. 
$\mathrm{DECH}$, permite calificarlas como peculiares. Precisamente esa peculiaridad hace pensar en su carácter neolatino o de creación romance, pues -ivo, a pesar de ser un sufijo culto, es muy productivo en castellano y tiene la vitalidad suficiente para favorecer la creación de otras voces a partir de bases participiales, hoy y en otros momentos del pasado de nuestra lengua (García de Diego 1914: 195, Fernández Ramírez 1975). Sin embargo, el examen del proceso de traducción latín-castellano, más allá de los datos lexicográficos, obliga a replantear la consideración inicial de 'neolatinismo'.

\section{Formaciones léxicas en -ivo: ¿creación castellana o herencia latina?}

\subsection{Testimonios lexicográficos latinos}

La no aparición de muchas de estas formaciones en otros textos (coetáneos o no) puede hacer pensar que se trata de creaciones propias de la traducción castellana, a imitación de las latinas, ${ }^{11} \mathrm{y}$, en consecuencia, de 'neolatinismos', según la interpretación de Pharies (2002: 371). Esta autor sitúa en el siglo XV la aparición de la primera oleada de formas en -ivo, latinismos, unos, por la existencia de la forma correspondiente en latín o latín tardío; y neolatinismos, otros, por la inexistencia de esa correspondencia, probada presumiblemente por la no documentación en los repertorios léxicos. ${ }^{12}$

Bastaría encontrar un testimonio en diccionarios de latín tardío y medieval para que hubiera que revisar la etiqueta de 'neolatinismo' aplicada a una voz así considerada: de hecho, la consulta de estos 'neolatinismos' en el Glosario de Du Cange así lo aconseja. ${ }^{13}$ Pero no sólo eso: el cotejo con la fuente latina, base de la traducción, revela que estas formas están ya en latín, en el latín de estos textos medievales, lo que prueba la impropiedad de esa caracterización. Parece, entonces, que en la consideración o no de una voz como 'latinismo' o 'neolatinismo' no sólo hay que comprobar la documentación en repertorios léxicos,

11 Se trata, entonces, del cultismo morfológico; esto es, de la influencia morfológica del latín a través de elementos de derivación cultos con profusión en castellano (Clavería Nadal 1991: 23).

12 Al decir que la primera oleada de latinismos dotados de sufijo comienza en el siglo XV cita los siguientes ejemplos acusativo (1435), lat. accusativus < accuso-are-atum 'acusar'; excesivo (1438), lat. tard. excessivus < excedo -ere -ssum 'ir más allá de’; motivo (1438), lat. tard. motivus $<$ moveo -ere, motum 'mover'; y una serie de ejemplos que se documentan en 1440, cf. adjetivo (adjectivus <adjicio -ere -ectum 'arrojar en'), atractivo (lat. tard. attractivus < attraho -ere -ctum 'atraer'), defensivo (lat. tard. defensivus < defendo -ere -sum 'defender'), intelectivo (intellectivus 'teórico' < intellego -ere -ctum 'comprender'), negativo (negativus < nego -are -atum 'decir no', 'negar'), primitivo (primitivus < primitiae -arum 'primicias'), prohibitivo (lat. tard. prohibitivus < prohibeo -ere -itum 'prohibir') y ofensivo (lat. tard. offensivus < offendo -dere -sum 'chocar, herir', 'ofender'). El flujo de latinismos continúa hasta el siglo XVIII y después (Pharies 2002: 371).

13 Nutritivo lo da Pharies (2002: 237) como 'neolatinismo', pero aparece documentado en MLWL, c. 1190 , c. 895 . Du Cange recoge abortivo, colativo, comunicativo, concretivo, efectivo, especulativo, excesivo, figurativo, fugitivo, laxativo, mundificativo, pasivo, penetrativo, potestativo, positivo, receptivo, representativo, retentivo, resuntivo. 
sino que es necesario cotejar el texto analizado con su posible fuente latina, algo más necesario aún cuando podemos constatar que textos no literarios como esta enciclopedia no suelen ser utilizados en la elaboración de los repertorios lexicográficos latinomedievales.

\subsection{Texto latino como fuente}

El texto fuente, base de la traducción, adquiere importancia para explicar tanto los 'latinismos' como los 'neolatinismos': si el punto de partida es el latín, es razonable que se conserven formas latinas y que la fidelidad de la traducción lleve a su mantenimiento. En el momento en que se hace la traducción, no es lo mismo que un texto de nueva creación, sin base latina, presente latinismos, que lo haga otro que traduce un original latino: en el primer caso, el elemento latino aparece conscientemente; en el segundo, lo hace por lo que se ha dado en llamar 'inercia'. Como señala Morreale (1977: 35):

El fenómeno de adopción de los latinismos que caracteriza por su intensidad al castellano de la Baja Edad Media, suele señalarse por contraste con la propensión hacia lo vernáculo de la época alfonsí. Lo hallamos calificado bajo la rúbrica de la innovación creadora (aun 'contra' la lengua) cuando el objeto de análisis es la obra de un escritor, en particular, de un poeta; bajo la del trasvase mecánico, cuando es un escritor mediocre, o, en particular, un traductor. ${ }^{14}$

En la Baja Edad Media y en la época premoderna (siglos XIV a XVI) se produce la introducción de la mayor parte del léxico culto contenido en español (Bustos Tovar 1974: 281; Harris-Northall 1999). Se recurre al latín para 'llenar huecos en el vocabulario conceptual de la lengua vernácula' (Dworkin 2004: 649), a través de latinismos destinados a enriquecer y elaborar el 'rudo romance', como lo calificaba el Marqués de Santillana, y de otros que desplazan a palabras ya existentes. Son textos literarios en los que se pretende conservar el espíritu y la letra de la tradición clásica grecolatina (Lapesa 1957).

En las obras técnicas, no literarias, la situación es distinta: el latinismo se justifica por la crítica que hacen los prólogos acerca de la pobreza léxica del castellano; la pretensión es escribir en castellano con palabras castellanas y cuando no es posible se recurre al latín. ${ }^{15}$ En el prólogo del PDC no se habla de la traducción como problema, algo normal en otros textos, ${ }^{16}$ sencillamente porque es la fidelidad con el texto latino lo que lleva al traductor a mantener el latín, los

14 Había, incluso, distintos grados de traducción, como también apunta Morreale (1959: 7): 'parece, pues, natural que cuando un libro estaba destinado a una colección particular, para que algún noble pudiera leer en él “algunas vezes ... y recrear el espíritu”, el esfuerzo de transfusión y verdadero romanceamiento debía de ser menor que cuando la traducción iba a servir como instrumento auxiliar para la vida litúrgica (como en las primeras traducciones de la Biblia del hebreo), o cuando formaba parte de un amplio programa de vulgarización del saber (como en el caso de las versiones bíblicas de la época alfonsina).'

15 Vid. los prólogos editados por Mancho Duque (2001).

16 Los traductores se quejan de la dificultad para traducir palabras abstractas - sobre todo en latín tardío - tecnicismos filosóficos, etc. (Morreale 1959: 8-9). 
latinismos. Si el afán vulgarizador lleva a cambiar el latín por el castellano, el traductor del PDC, al mantenerlo, contribuye a crear una norma léxica culta en la que tienen cabida latinismos y neolatinismos al lado de las voces castellanas: ${ }^{17}$ a ello se refieren Alvar y Mariner (1960: 34-35) cuando dicen que la traducción de textos latinos fue 'un camino seguro para la penetración de latinismos'. ${ }^{18}$ O sencillamente el problema que le hubiera supuesto al traductor introducir cambios le llevó a no hacer nada (así se explica la forma transumtivo por 'trasladado' o 'copiado'; vid. infra). ${ }^{19}$ Esa era la recomendación de Pedro López de Ayala al traducir De consolatione de Boecio:

Como sea muchas vezes que por la diuersidat de las lenguas se fallen algunas palabras que no son mudables sin gran daño suyo ... donde tal diçion fallare quedara en su propio vocablo o se trocara por el mas cercano que en nuestro vulgar yo fallare; ${ }^{20}$

modo de proceder que no se considera estrictamente hacer una traducción, pues, como apunta Morreale (1959: 9),

solo cuando las palabras se ponen 'de fuera', escogiéndolas del patrimonio de la lengua, nos hallamos frente a una verdadera traducción (...) De un modo general puede decirse que éste es un fenómeno más característico del siglo XIII que del XV por la voluntad de la lengua de dejar de ser latina. En cambio, si el traductor se limita a buscar el vocablo 'más cercano', tan cerca puede quedarse del original, que la suya es una lengua neutra, un latín apenas castellanizado.

De la comparación del PDC castellano con el texto latino se derivan los siguientes hechos, caracterizadores de la traducción:

1) -ivo en los textos latino y castellano. La coincidencia en los dos textos se manifiesta de dos maneras:

1.1) con la misma forma en los dos textos:

PDC cast.: [Virtud] Pulsiva que expele las cosas superfluas que no se pueden ni ayuntar ni asemejar a los miembros animales. E por esto asi como apetitiva obra por el calor

17 Si el traductor no hubiera tenido interés por el latín, habría sustituido todas las formas en -ivo del original, como hizo el traductor que romanceó las Etimologías isidorianas, cambiando appellativos por llamaderos o llamadizos, derivativos por traedizos, possesivos por mantenedizos, meditativos por pensadizos o translativa por trasmudadiza (González Cuenca 1983: 50). Pero es precisamente el deseo de crear una norma léxica culta lo que le lleva a mantenerlos y a explicarlos, en muchos casos, a través de los dobletes o duplicaciones léxicas y de paráfrasis metalingüísticas. La función es similar a la que tienen las correspondencias en los romanceamientos bíblicos o las 'definiciones' y 'etimologías' de las obras de Alfonso X el Sabio; son, como explica Clavería (2004: 479), 'fórmulas que entrañan un emparejamiento de una forma latina que más adelante será admitida como latinismo, a la que en aquel momento se le proporciona equivalente romance'.

18 No obstante, hacen la observación de que 'conviene no dejarse deslumbrar: el caudal léxico positivo es evidente, pero no menos cierto es también que las traslaciones bíblicas muestran muchos latinismos que no han tenido existencia sino en la pluma de los traductores romances (horribilidad, nefario, coescripciones, transfletar, etc.) (Alvar y Mariner 1960: 35).

19 En el DECH s.v. sumir sólo trasunto cuyo significado en la Edad Media es 'copia', del lat. transsumere 'transportar'; trasuntar 'copiar'. Sí documenta una forma trasuntivamente.

20 Citado por Morreale (1959: 9). 
e sequedad, assi la digestiua obra por el calor e umidad e la retentiua por frialdad e sequedad e expulsiua obra por la frialdad e umidad. (fol. 28v)

PDC lat.: Item expulsiva que superflua membris tracta eis nullatem assimilando necessaria expellit. Et ideo sicus vis appetitiua opera cum calido et sicco et digestiua cum calido humido et retentiua cum frigido et sicco, sic expulsiua cum frigido et humido operatur.

PDC cast.: Estas dos virtudes ynformatiua que enforma e ynmutatiua que muda obran fasta tanto que la cosa engendrada como plantas e animales sean en su ser acabados y al ora que son complidos ellas cesan de obrar (fol. 28v)

PDC lat.: Haec autem due virtutes sunt immutatiua et informatiua non diurius operantur nisi quosque res generata ut animal vel planta inesse nature compleat.

1.2) con distinta forma en los dos textos:

PDC cast.: Assi que la virtud vital extendiendo el coraçon atrae el aire mediante el pulmon e lo embia por las venas a los otros miembros del cuerpo assi que esta mesma virtud por la virtud ampleativa e por la virtud restritiva obra el resollo en los animales (fol. 28v)

PDC lat.: Et ista virtus per virtute dilatativa cordis e constrictiua anhelitum in animali opertur.

PDC cast.: La carne de los galapagos de los montes es mediçinal. Ca es recuperatiua de la virtud perdida por enfermedad e por esto es ella buena a los que son tisicos e ethicos (fol. 295r).

PDC lat:: Carnes vero eius que habitant in nemoribus sunt medicinales et virtutis resumptiue e inde valent ... et putrificis et consumptis.

De las dos posibilidades, la coincidencia en los dos textos es lo general y, por tanto, lo más abundante; las diferencias son escasas. Sólo en este último caso podrá hablarse de 'neolatinismo', si se comprueba la inexistencia de la forma en otros textos y repertorios léxicos (es el caso de ampleativo). ${ }^{21}$ La aparición del latinismo o neolatinismo en el texto castellano es tan novedosa que, en algunos casos, se acompaña de una explicación.

2) -ivo en latín y perífrasis o recreación lingüística en castellano. Esta situación pone de manifiesto que las posibilidades que brinda -ivo en latín no son siempre trasladables al castellano y por ello la traducción cambia el texto latino. Se explica así que -ivo sea más abundante en latín que en castellano (a pesar de que su presencia en esta lengua es también notable). Dos son las razones de la sustitución: por un lado, la inexistencia de las formas latinas en castellano (cf. uritivo, de lat. uro-as -are 'quemar'):

PDC cast.: Contra el cançer deve usar el enfermo de cosas corrosivas e quemantes que quemen e roen la mala carne; contra la fistula deve usar de cosas desecativas e consumitivas e que alinpian el podre e la materia de la fistula e si esto no le aprouecha es bueno ponerle en las manos de los çirurgianos, ca mas segura cosa es que una parte del cuerpo sea quemada o cortada que si todo el cuerpo se pierda. (fol. 110v).

21 No está en el DECH (s.v. ancho, t. I, pág. 254) ni en el CORDE. 
PDC lat:: Cancer vero uritiuis et carnis mortue corrosiuus est utendum, contra fistula

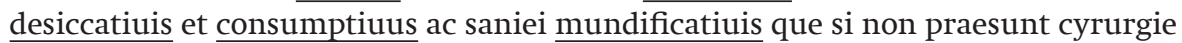
conmmutrant tuti enim est ut aliqua particula corpis sani corrupta urat vel percidat quae reliqua pars in posterum corrumpat;

y, por otro, el desarrollo de la traducción, si otras formas en -ivo están presentes:

PDC cast.: Ha virtud colativa o abridora e disolutiva e adelgazadora e humedeçe el vientre sin ningun mordimiento e mundifica e alimpia el estomago e ha virtud de ablandar las asperezas de los pechos e de los livianos e de clarificar la voz e quita la tos e ronquedad e restaura la humidad consumida (fol. 254v).

PDC lat.: Habet virtutem colatiuam, dissolutiuam, extenuatiuam, et ventris absens ulla morsura humectativam, et stomcahi mundificatiuam, asperitatis pectoris et pulmonis lenificatiuam, vocis clarificatiuam tussis et raucedinis ablatiuam, humiditatis consumpte restaurativam.

En otros pasajes, la forma que evita - es el caso de inflativo -, por la presencia de otros adjetivos en -ivo,

PDC cast.: Item la corteza del trigo o salvado ha virtud colativa e mundificativa mas que su harina. [...] El trigo reziente e nuevo es de muy poco nutrimento. E cuando es comido crudo es flematico e hincha e causa dolor en los costados (fol. 247r)

PDC lat.: Item cortex tritici sive furfur habet virtutem colativam et mundificatiuam ... Triticum recens et nouum parui est nutrimenti et quando comeditur crudum flegmanticum est et inflatiuum et in lateribus dolorem conmovet et rugitum.

la escribe unos folios después:

PDC cast.: Ha la viraga una fuerça aguda e en alguna manera ponçoñosa inflativa e ventosa (fol. 254r)

PDC lat.: Habet autem zizania vim acutam et quidam mom venenosam inflatiuam et ventosam.

3) Expresión lingüística o forma distinta a -ivo en latín y forma en -ivo en castellano. Frente a la semejanza en las dos lenguas, esta sería la otra posibilidad teórica cuando los textos latino y castellano tienen diferencias. Apenas hay ejemplos que muestren esta situación; la razón está en el carácter marcado y foráneo del sufijo -ivo; por ello, no es un recurso utilizado por el traductor (si no le viene marcado por el texto latino):

PDC cast. Hay otros nombres transumtivos que son tomados de las creaturas do son propiamente e son atribuydos a Dios por una similitud ympropiamente (fol. 10v). PDC lat. Sunt autem quedam nomina transsumpta a creaturis quibus utiis scriptura quem intendit aliquas exponere conditiones creatoris.

PDC cast.: Mas este calor es en dos maneras: es a saber solar o celestial y engendrante que salua y engendra, ca por el son alguna vez las ranas en el ayre creadas. Otro es calor elemental y engendratiuo que corrompe e consume, como paresce de un espejo ardiente (fol. 37r)

PDC lat.: Est aut duplex caliditas, caliditas solares sive celestis generans, et haec est $\underline{\text { saluatiua et generativa. Alia est elementaris et generata et haec est corruptiua. }}$ 
Los testimonios extraídos del PDC son, entonces, latinismos; pero 'latinismos' (rara vez puede hablarse de 'neolatinismo', en el sentido de Pharies 2002) mediatizados por el tipo de texto en que aparecen. El texto castellano es pretendidamente fiel al texto latino: se procura la inserción de latinismos a toda costa y de todo tipo - feble, renes, servitud, tardivo, etc. - y, por supuesto, formas en -ivo. El traductor sólo cambia aquello que le da problemas: lo normal, entonces, son los ejemplos del grupo 1; los del 2 no surgen por un interés innovador del traductor, quien procura no salirse del modelo latino, sino por la dificultad que le supone trasladar al castellano una estructura sintáctica basada en la frase nominal en vez de en la verbal, como se verá más adelante. Los ejemplos de 3 son resultado del ejercicio de la traducción y del conocimiento, por parte del traductor, de la lengua latina y de las posibilidades derivativas del castellano: a medida que avanza la traducción puede el traductor hacer uso de formas en -ivo no presentes en el original latino. Es la manera que tiene de no apartarse del latín, de no ser castizo (Menéndez Pidal 1972: 69). Precisamente la fidelidad del texto castellano con el latín y, por consiguiente, el mantenimiento de las formas en -ivo del original latino, lleva a hacer unas matizaciones sobre el concepto de 'neolatinismo'.

\section{Latinismo, neolatinismo y neologismo}

La documentación en el texto latino de los ejemplos citados lleva a cambiar la etiqueta de 'neolatinismo' por la de 'latinismo'. Además, considerar 'neolatinismo' aquella forma creada sobre el modelo latino no está exento de problemas, problemas que atienden a la propia caracterización de 'neolatinismo' y a la conveniencia de su acuñación junto a 'latinismo': si por 'neolatinismo' se entiende aquella creación léxica romance de acuerdo con el modelo latino, ¿por qué no se habla de 'neologismo' romance o castellano? Por el contrario, si 'neolatinismo' es una voz nueva latina, ¿por qué no se habla, sin más, de 'latinismo'? Sólo es entendible la denominación 'neolatinismo' si con ella se quiere nombrar una nueva realidad.

Es muy probable que con el término 'neolatinismo' se quiera designar una nueva oleada de voces latinas, en un momento en que el préstamo latino tiene mucha fuerza: se trataría de nuevos latinismos dentro de los latinismos. El problema de la clasificación de Pharies (2002: 371) y la necesidad de aclarar el concepto, está en que llama 'latinismo' a los elementos léxicos que puede documentar en latín y 'neolatinismo' a los que no, esto es, a creaciones léxicas romances, sencillamente meros neologismos. ${ }^{22}$

La solución al problema podría estar en plantear si es necesario o no el término 'neolatinismo' al lado de 'latinismo' u ofrecer para 'neolatinismo' otra explicación. Los ejemplos del PDC y los extraídos de los textos médicos citados por Pharies (2002), parecen mostrar que lo que se quiere llamar 'neolatinismo' es: a)

22 Vid. en nota 12 la lista de latinismos en -ivo que cita con la correspondiente forma latina entre paréntesis. 
un tipo de latinismo, b) no literario o estético, c) presente en un tipo particular de textos y d) surgido en una época determinada, que e) llega al castellano y, por lo general, f) tiene una vida efímera. Es, efectivamente, un 'nuevo latinismo', que frente al 'latinismo' literario, presente en textos clásicos latinos y documentado en los españoles desde el siglo XIII, aparece en textos no literarios o técnicos, surge en textos de latín tardío o medieval y tiene su esplendor en castellano a lo largo del siglo XV. 'Neolatinismo' sería, entonces, la denominación para un nuevo grupo de latinismos con unas características determinadas.

No es, no obstante, la primera denominación para latinismos de un determinado tipo y de una determinada época. Menéndez Pidal (1972: 69) habla de 'neologismo latinista' para referirse a los préstamos latinos en castellano en época alfonsí; Alvar y Mariner (1960: 24) denominan 'latinismo póstumo' a la creación de voces con elementos latinos:

En efecto, constituye el 'latinismo póstumo' uno de los elementos de mayor interés entre los latinismos del castellano; resulta ser una de las pruebas más evidentes de la influencia del latín y de la pervivencia de su vitalidad derivativa. Pero es muestra, también, de su capacidad composicional en un grado tal vez superior al que ofrecía el propio latín, que, como es sabido, fue más bien reacio a la formación de compuestos, sobre todo, en época clásica.

Los latinismos póstumos se deben, bien a la combinación de elementos totalmente latinos, pero que no se dieron reunidos en la lengua de origen (por ejemplo: multitudinario, posesionar), bien a la aplicación de algunos de ellos - generalmente instrumento de derivación o de composición - a otros elementos importados de lenguas ajenas (p. ej. standardización, subjefe). Los del segundo tipo son particularmente abundantes, dada la gran cantidad de sufijos y prefijos de forma culta que posee el castellano, con una vitalidad que, sobre todo en éstos, supera incluso a la de los evolucionados (cfr. bi-, dis-, ex-, in- en sus diversas formas, super-, sub-, trans-, vice-; entre los sufijos, -ancia, -ario, -ción, -encia, -eo,-ivo - especialmente en las combinaciones -tivo, -sivo, -xivo, etc.).

\section{Consideración de las formaciones léxicas en -ivo en castellano}

\subsection{Latinismo y neolatinismo como tecnicismo}

Estas formaciones léxicas son extrañas en castellano. Y lo son por varias razones: a) porque no son propias de textos literarios (como se desprende de los datos del $\mathrm{DECH}$; b) porque son consideradas tecnicismos y, por tanto, son explicadas, en muchos casos, por el traductor y c) porque, derivado de las dos razones anteriores, son formas caracterizadoras de la tipología textual. Es el tipo de texto, el registro al que pertenece, el que determina la aparición de estas formas: el mantenimiento de la forma latina se explica no sólo por el carácter culto del texto, sino por el valor técnico recibido. ${ }^{23}$ Así lo prueba el proceso de sustantivación que

23 Pascual (1996: 40-41) señala que en la actualidad 'con cierta frecuencia se recurre a este sufijo -ivo para la creación de tecnicismos que expresan finalidad, sentido activo, pasivo o relación con algo. Son sentidos derivados del fundamental que tuvo en el pasado ... el de expresar los efectos que tenían los remedios medicinales.' Y cita las formas aperitivo, 
convierte hoy en sustantivos a algunos adjetivos que acompañan a palabras como medicamento, potencia, virtud, caso, etc., pertenecientes a los registros médico, filosófico y lingüístico: abstersivo, interrogativa, o ablativo entre otros. ${ }^{24}$

\subsection{De la sintaxis latina al léxico castellano}

Pero lo interesante es que no son solamente latinismos léxicos; se trata, en realidad, de latinismos sintácticos reconvertidos en latinismos léxicos: ${ }^{25}$ el mantenimiento de estructuras sintácticas latinas con -ivo hace que sean reinterpretadas como estructuras fijas o relativamente fijas y de ahí se deriva, en algunos casos, su utilidad como tecnicismo; precisamente por ese carácter técnico y culto se conservan muchas hoy en español, frente a lo que sucede con los participios de presente, que por no formar parte de estructuras fijas - por ejemplo, tecnicismos - se pierden.

La presencia de -ivo está más relacionada con la sintaxis que con el léxico; el traductor no sólo respeta el texto latino, sino su sintaxis y por ello traslada fielmente formas fijas o clichés (por ejemplo, compuestos sintagmáticos formados sobre la voz virtud) al castellano. Este hecho no es nuevo en la traducción del PDC, pues, como ha señalado Morreale (1977: 53), el mantenimiento de latinismos en la traducción es paralelo al mantenimiento de la sintaxis:

en el caso del romanceamiento contenido en E[scorial]4, los muchos latinismos que contiene en el contexto de una sintaxis a menudo adherida rastreramente al modelo, parecen trasvasados por inercia; puntos muertos que el traductor arrastra a la par de las palabras que deja en latín y que entremezcla de espacios dejados vacíos por falta de comprensión.

No obstante, la abundancia de formas en -ivo en el texto latino y la repetición excesiva de una estructura ajena al castellano, le lleva a introducir cambios mediante perífrasis. Los siguientes fragmentos sirven para ilustrarlo:

PDC cast.: Es eso mesmo una virtud que deduze las baxas cosas a las altas: es atractiva e consumidora de las cosas superfluas e de las suçiedades y en diversas materias y es produtiva que produze diversos effectos e opositos porque tanbien es dicha molificativa e rarificativa deretiente e abriente. E por el contrario es alguna vez condensatiua y enduratiua, opilatiua, otras vezes es conseruatiua y otras vezes corruptiua. No menos por su propia virtud es mudadora de los sabores (fol. 37r) PDC lat.: Et ideo nunc invenit rarefactiua et remollificatiua, liquefactiua et aperitiua et conuerso, nunc condensatiua, e induratiua, ostrictiua et opilatiua, nunc etiam $\underline{\text { saluatiua, nunc corruptiua. Est etiam virtute propia saporum inmutatiua. }}$

carminativo, confortativo, consolidativo, desecativo, desopilativo, exudativo, lenificativo, lenitivo, molificativo, mundificativo, paliativo, refrigerativo.

24 Así lo prueba tanto la marcación técnica como la definición (vid. 22 $2^{a}$ ed. DRAE).

25 Alvar y Mariner (1960: 19-20) señalan como cultismo sintáctico el uso del participio de presente, así como 'la transformación del período de acuerdo con los moldes latinos': las formaciones en -ivo latinas y castellanas se comportan de manera similar a los participios de presente; y, en cuanto a la construcción del período, en el PDC, al tratarse de una traducción, no hay transformación sino mantenimiento. 
PDC cast.: El açucar es bueno e templado en sus calidades: e por esto segund dize Ysaac en las dietas. Ha virtud colativa o abridora e disolutiva e adelgazadora e humedeçe el vientre sin ningun mordimiento e mundifica e alimpia el estomago e ha virtud de ablandar las asperezas de los pechos e de los livianos e de clarificar la voz e quita la tos e ronquedad e restaura la humidad consumida. (fol. 254v).

PDC lat.: Habet virtutem colatiuam, dissolutiuam, extenuatiuam, et ventris absens ulla morsura humectativam, et stomcahi mundificatiuam, asperitatis pectoris et pulmonis lenificatiuam, vocis clarificatiuam tussis et raucedinis ablatiuam, humiditatis consumpte restaurativam.

PDC cast.: Es pues el olor tanbien manifestativo de su subjeto e mutativo que muda el aire por su incorporaçion e muda el espiritu animal. E es difusivo que se difunde y esparze por el ayre. y es penetrativo que penetra por el atraymiento del aire las entrañas del çelebro e consumptivo que consume por su calor los humores e los fluxos noçivos se restriñen y es reparativo que repara por su puridad los espiritus y es confortativo que conforta la virtud del coraçon y es conuersivo que conuierte el aire a su similitud e gasta o destruye los hedores e cubre las pudredumbres e causa assi de los sentidos de los animales como de los hombres delectaçion (fol.303v) PDC lat.: Est itaque odor sui obiecti manifestativum, spiritus animalis inmutativuus, suis prius per aera diffusiuus ad interiora cerebri per flatum aeris vel attractum penetratiuus suo calore humores consumptiuus e fluxus nociui restrictiuus, sua puritate spiritu reparativus, sua virtute debilitatis cordis confortativuus aeris in suam similitudinem conuersiuus fetoris repercusivus et putridinis palliativus deletationis in sensu animalium sicut e hominum causatiuus.

Los cambios introducidos por el traductor se explican por el deseo de aligerar el texto, lleno de adjetivos deverbales, pero también por su carácter técnico y, por qué no, por lo crudamente latinos y novedosos que le parecen algunos.

Esta explicación de los hechos y, en consecuencia, de la razón de ser de formaciones en -ivo en el PDC sólo es posible gracias al cotejo con la base latina. Y precisamente es en el latín y en el proceso de traducción donde reside la explicación a la presencia en castellano de un sufijo como -ivo, morfológicamente caracterizado como culto. Y podría decirse, además, que lo que se interpreta como un mero rasgo léxico de un texto castellano, es, en realidad, la consecuencia de trasladar a esta lengua - o mantener - un hecho sintáctico normal en el texto latino.

\subsection{Pervivencia de estas formaciones léxicas en -ivo}

En apoyo de una consideración más sintáctica que léxica de la presencia de estas formas en textos castellanos, así como de una necesaria reinterpretación del concepto de 'neolatinismo', acorde con las matizaciones hechas más arriba, se encuentra su abandono temprano en español (al igual que muchas formas de participio de presente, como llorante o tallante, también en el $P D C$ ), siempre que no se hayan conservado como tecnicismos y, por tanto, no hayan fijado su uso en un registro o contexto sintáctico determinado: compruébese, por ejemplo, esta doble consideración, la de arcaísmo y tecnicismo, a propósito de la voz agre- 
gativo. ${ }^{26}$ Hoy la mayoría de las formas citadas en el texto son arcaísmos (o sencillamente no se recogen en los diccionarios): así sucede con apurativo, combustivo, odorativo, etc.

\section{Conclusiones}

Lo expuesto hasta aquí pone de manifiesto la relación entre tipología de voces y tipología textual. Precisamente por ser una enciclopedia, cuyo contenido en muchas partes es de carácter científico-técnico, aparecen voces tan peculiares (que hasta el momento sólo se documentan aquí). No se trata de creaciones romances (neologismos); y parece probado que tampoco es adecuada la denominación 'neolatinismo', pues existen en el latín medieval del texto base de la traducción (es decir, son latinismos). Sólo se justifica esa etiqueta si se entiende en el sentido de creaciones latinas propias de un tipo particular de texto. El cotejo de las formas en repertorios y corpus léxicos así lo prueba.

A esta conclusión se llega a partir del examen de las formas en -ivo. Queda pendiente el análisis de otras formas morfológicas (otros sufijos), así como otras formaciones léxicas (por ejemplo, latinismos crudos) con el objeto de apoyar la conexión tipo de texto - tipo de léxico, todo ello teniendo presente siempre el modo como se efectúa la traducción.

\section{Apéndice}

Las formas con sufijo -ivo contenidas en el texto están extraídas de la concordancia de la edición citada en la bibliografía. Se respeta la grafía y se señala entre paréntesis el número de ocurrencias en el texto. La frecuencia de aparición es escasa, en la mayoría de los casos un solo testimonio. El reparto de formas distintas es el siguiente: 49 formas en -ivo, 16 en -ivos, 75 en -iva y 26 en -ivas.

Formas en -iva

Actiua (13), Ampleatiua (1), Apetitiua (4), Aprehensiua (2), Atractiva (2), Atratiua (5), Attratiua (2), Auditiua (6), Aume $<$ >tatiua (1), Aumentatiua (2), Biuificatiua (4), Ca $<$ n>titatiua (1), Calificatiua (1), Caritatiua (2), Catiua (1), Cautiua (1), Co $<m>b u s t i u a$ (1), Co $<m>$ prehe $<n>$ siua (1), Co $<n>$ fortatiua (4), Co $<n>$ seruatiua (2), Colatiua (3), Colectiua (1), Comprehensiua (1), Comunicativa (2), Condensatiua (1), Confortantiua (1), Confortatiua (1), Conjuntiua (1), Conosc'itiua (1), Conseruatiua (4), Consideratiua (1), Conte $<m>$ platiua (1), Corrosiua (2), Corruptiua (1), D<e>sicatiua (1), Deliberatiua (1), Demostratiua (1), Digesti<u>a (1), Digestiua (10), Disolutiua (1), Diuisiua (1), Efectiua (2), Enduratiua (2), Enfectiua (1), Especulatiua (1), Espulsiua (6), Estimatiua (3), Exc'ec'iua (1), Exc'esiua (8), (Expulsiua (5), Extimatiua (1), Formatiua (2), Generatiua (11), Jnflatiua (1), Judicatiua (1), Lauatiua (2), Laxatiua (10), Memoratiua (5), Mitigatiua (1), Molificatiua (5), Mordicatiua (1), Mortificatiua (4), Motiua (16), Mu<n>dificatiua (2), Noc'iua (3), Nudritiua

26 DRAE, $22^{\text {a }}$ ed. s.v. agregativo: $1^{\text {a }}$ acep. ant. 'Que agrega o tiene virtud de agregar' y $2^{\mathrm{a}}$ acep. Med. 'Dicho de una píldora: Compuesta de diversos purgantes.' 
(1), Nutritiua (17), Odoratiua (3), Op<er>atiua (1), Operatiua (2), Opilatiua (3), Ordenatiua (2), P<er spectiua (1), P<er>spetiua (2), Pasc'itiua (1), Pascitiua (2), Pasiua (5), Penetratiua (5), Perfectiua (2), Perspectiua (1), Perspetiua (7), Positiua (2), Potestatiua (1), Produtiua (1), Progresiua (1), Pulsiua (1), Purgatiua (4), Rarificatiua (1), Rec'etiua (2), Recuperatiua (1), Redutiua (1), Rep<er>cusiua (1), Rep<re>sentatiua (1), Repercusiua (1), Restritiua (1), Resuntiua (1), Retardatiua (1), Rete<n>tiua (2), Retentatiua (1), Retentiua (7), Sensitiua (24), Sensytiua (1), Solutiua (1), Sotiliatiua (1), Suc'eptiua (1), Suc'esiua (2), Tardiua (2), Trasmutatiua (1), Vegetativa (18), Visiua (5), Viua (7), Ylluminatiua (1), Ymaginati<u>a (1), Ymaginatiua (7), Ync'isiua (1), Ynformatiua (6), Ynmutatiua (2).

Formas en -ivas

Actiuas (10), Alteratiuas (1), Atratiuas (1), Co $<n>$ dutiuas (1), Co $<n>$ fortatiuas (4), Co $<n>$ seruatiuas (1), Co $<n>$ solidatiuas (1), Co $<n>$ stipatiuas (1), Co $<n>$ sumitiuas (1), Co $<n>$ tenplatiuas (1), Confortatiuas (1), Contemplatiuas (1), Corrosiuas (4), Corruptiuas (1), Desecatiuas (1), Desopilatiuas (1), Disolutiuas (2), Enflamatiuas (1), Especulatiuas (1), Jnpeditiuas (1), Laxatiuas (4), Maduratiuas (1), Molificatiuas (1), Mollificatiuas (1), mordicativas (1), Mortificatiuas (1), Mu<n>dificatiuas (1), Mundificatiuas (1), Nudritiuas (1), Opilatiuas (1), P<er>cusidas (1), P<re >seruatiuas (1), Pasiuas (6), Prerrogatiuas (1), Remolitiuas (1), Rep<er>cusiuas (1), Restauratiuas (3), Restrictiuas (1), Solutivas (1), Suc'esiuas (1), Viuas (1).

Formas en -ivo:

Abortiuo (1), Actiuo (19), Adjectiuo (1), Agregatiuo (1), Aleuiatiuo (1), Apuratiuo (1), Atiuo (2), Atratiuo (3), Auditivo (2), Aumentatiuo (1), Catiuo (1), Colatiuo (1), Confortatiuo (3), Consumptiuo (1), Conte $<m>$ platiuo (1), Conuersiuo (1), Creatiuo (1), Descoloratiuo (1), Difusiuo (1), Digestiuo (1), Disolutiuo (1), Engendratiuo (1), Exc'esiuo (10), Exemplificatiuo (2), Extenuatiuo (1), Figuratiuo (1), Generatiuo (1), Genetiuo (1), Jnc'isiuo (1), Laxatiuo (1), Manifestatiuo (1), Mutatiuo (2), Noc'iuo (2), Nutretiuo (1), Nutritiuo (8), Opilatiuo (1), P<er>c'eptiuo (1), Pasiuo (1), Penetratiuo (2), Progresiuo (1), Prouocatiuo (1), Pungitiuo (1), Purgatiuo (4), Reçeptiuo (2), Redutiuo (2), Reparatiuo (1), Sensitiuo (1), Speculatiuo (1), Susc'etiuo (1), Tardiuo (3), Vaporatiuo (1).

Formas en -ivos:

Abstratiuos (1), Actiuos (3), Adiectiuos (3), Adjectiuos (4), Adjetiuos (6), Cautiuos (2), Co $<n>$ fortatiuos (3), Co $<n>$ sumiti $<u>0 s$ (1), Coloratiuos (1), Comunicativos (1), Concretiuos (1), Confortatiuos (2), Contemplatiuos (2), Exçesiuos (1), Fugitivos (1), Generatiuos (2), Genetiuos (1), Motiuos (1), Noc'iuos (4), Nudritiuos (2), Nutritivos (1), Ordenatiuos (1), Partitiuos (1), Pasiuos (1), Penetratiuos (1), Priuatiuos (1), Purgatiuos (1), Reçeptiuos (1), Resolutiuos (1), Susta<n>tiuos (2), Sustantiuos (4), Transumtiuos (1), Visiuos (1), Viuos (2), Ynfetiuos (1).

\section{Obras citadas}

ADMYTE, 1994. Archivo Digital de Manuscritos y Textos Españoles (Madrid, Micronet).

Alvar, Manuel y Sebastián Mariner, 1967. 'Latinismos'. Enciclopedia de Lingüística Hispánica (Madrid, CSIC), vol. II, pp. 3-49. 
Baxter, J. H. y C. Johnson 1934. Medieval Latin Word-List from British and Irish Sources (London, Oxford University Press), citado MLWL.

Bustos Tovar, José Jesús, 1974. Contribución al estudio del cultismo léxico medieval (Madrid, Anejos BRAE).

Clavería Nadal, Gloria, 1991. El latinismo en español (Barcelona, Universitat Autònoma de Barcelona).

Clavería Nadal, Gloria, 2004. 'Los caracteres de la lengua en el siglo XIII: el léxico', in Historia de la lengua española coord. R. Cano (Barcelona, Ariel), pp. 473-504.

Corominas, Joan y José Antonio Pascual, 1980-1991. Diccionario crítico etimológico castellano e hispánico. (Madrid, Gredos) 6 vols, citado DECH.

Du Cange 1883-1887. Glossarium mediae et infimae latinitatis, facsímil de Graz, 1954.

Dworkin, Steven N., 2004. 'La transición léxica en el español bajomedieval', in Historia de la lengua española coord. R. Cano (Barcelona, Ariel), pp. 643-56.

Fernández Ramírez, Salvador, 1975. 'Derivados españoles en -ivo', Archivum, 25: 323-27.

García de Diego, Vicente, 1914. Elementos de gramática histórica castellana (Burgos, Tipografía El Monte Carmelo).

González Cuenca, Joaquín, 1983. Las etimologías de San Isidoro romanceadas (Salamanca, Ediciones Universidad), vols. I y II.

Harris-Northall, Ray, 1999. 'Re-latinización of Castilian lexis in the early Sixteenth Century', Bulletin of Hispanic Studies, 62: 79-94.

Herrera, María Teresa, 1996. Diccionario Español de Textos Médicos Antiguos (Madrid, Arco Libros), 2 tomos, citado DETEMA.

Lapesa, Rafael, 1957. Santillana: la lengua literaria de Santillana. Madrid, Ínsula.

Mancho Duque, María Jesús, 2001. Pórtico a la Ciencia y la Técnica del Renacimiento (Salamanca, Junta de Castilla y León y Universidad de Salamanca).

Menéndez Pidal, Ramón, 1972. 'De Alfonso a los dos Juanes. Auge y culminación del didactismo (1250-1370)', Studia Hispanica in honorem R. Lapesa, I. (Madrid, Gredos), pp. 63-83.

Morreale, Margarita, 1959. 'Apuntes para la historia de la traducción en la Edad Media', Revista de Literatura, 15: 3-10.

Morreale, Margarita, 1977. 'Sobre el latinismo en los romanceamientos bíblicos: alternancias léxicas con el lexema patrimonial en dos testimonios de una misma versión de los Libros de los Macabeos (Esc. I.1.4 y Ac. Hist. 1)', RFE, 59: 33-45.

Pascual, José Antonio, 1996. El placer y el riesgo de elegir. Sobre los recursos derivativos del español (Salamanca, Universidad de Salamanca).

Pascual, José Antonio 1997-1998. 'El enfoque histórico en los procedimientos derivativos del léxico español', Voces, 8-9: 249-64.

Pharies, David, 2002. Diccionario etimológico de los sufijos españoles (Madrid, Gredos).

Real Academia Española, 2001. Diccionario de la Lengua Española (Madrid, Espasa Calpe), 22a edición, citado DRAE.

Real Academia Española. CORDE Corpus diacrónico del español, Banco de Datos en línea. Dirección URL: http://www.rae.es.

Sánchez, María Nieves y María Teresa Herrera, 1999. Textos y concordancias electrónicos del libro De las Propiedades de las Cosas de Bartolomé de Glanville (BNM I-1884), Madison, Hispanic Seminary of Medieval Studies, citado PDC.

Smith, Colin C., 1959. 'Los cultismos literarios del Renacimiento: breve adición al Diccionario crítico etimológico de Corominas’, Bulletin Hispanique, 61: 236-72. 
